This draft may differ slightly from the final version. Please cite the published version:

Barnes, Hilary \& Michnowicz, Jim. 2015. "Broad focus declaratives in Veneto-Spanish bilinguals: Peak alignment and language contact". Studies in Hispanic and Lusophone Linguistics, 8(1). 35-57.

\title{
Broad focus declaratives in Veneto-Spanish bilinguals: Peak alignment and language contact
}

\author{
Hilary Barnes and Jim Michnowicz \\ College of Charleston and North Carolina State University
}

\begin{abstract}
This paper examines peak alignment in Veneto-Spanish bilinguals in the small community of Chipilo, Mexico. We have two goals: First, to provide a description of the peak alignment patterns present in bilingual Chipilo Spanish. As Chipilo Spanish is in contact with a northern Italian variety (Veneto), we hypothesize that changes in peak alignment from monolingual norms, specifically regarding early peak alignment, may be due to transfer from Veneto. Second, we seek to compare the present data, based on controlled speech, to the results of a previous study on semi-spontaneous speech in Chipilo Spanish, contributing to the literature that compares methodologies in intonation research (see Face 2003). Our results show that bilinguals demonstrate early peaks in controlled speech, although to a lesser extent than in semi-spontaneous speech. We attribute this to contact with Veneto and a strong sense of ethnolinguistic identity that leads speakers to maintain features of a Chipileño variety of Spanish.
\end{abstract}

\section{Introduction}

This paper contributes to a line of research examining peak alignment in contact varieties of Spanish. Numerous studies have shown variability across Spanish dialects with respect to F0 peak alignment in stressed syllables in broad focus declaratives (McGory \& Díaz-Campos 2002, Sosa 1999, among others). Many varieties of Spanish display a delayed prenuclear peak alignment pattern, with the F0 contour rising throughout the stressed syllable and reaching its maximum point in the post-tonic syllable (Face 2003, Hualde 2005, McGory \& Díaz-Campos 2002, O’Rourke 2004, see de-la-Mota, Butragüeño \& Prieto 2010 specifically for Mexico City, and Willis 2005 for Puebla, Mexico). Nuclear peaks, on the other hand, normally display early peak alignment, with the peak aligned with the final tonic syllable of the utterance (see O'Rourke 2012 for an overview of these patterns). In addition to monolingual varieties of Spanish, peak alignment has been studied in a number of contact varieties, including Spanish in contact with English (Alvord 2006), Quechua (O'Rourke 2005), Basque (Elordieta 2003), Yucatec Maya (Michnowicz \& Barnes 2013) and the former language contact situation in Buenos Aires with Italian (Colantoni \& Gurlekian 2004, Colantoni 2011). Unlike most monolingual varieties of Spanish, some contact varieties show early prenuclear peaks in broad-focus declaratives, with the F0 peak aligned within the stressed syllable (Colantoni 2011, Colantoni \& Gurlekian 2004 for Buenos Aires Spanish, Elordieta 2003 for Basque Spanish, O'Rourke 2004, 2005 for Cuzco Spanish). Importantly, early peak alignment for prenuclear peaks does exist in non-contact varieties, but is most often associated with narrow/contrastive focus or emphatic speech, and generally is not found in broad-focus declaratives (Face 2001).

This paper will extend this research into an understudied language contact situation, that of Veneto-Spanish bilinguals in Chipilo, Mexico. Chipilo, founded by Italian immigrants in 1882, is a small community of approximately 4,000 people near the city of Puebla. Veneto continues to be spoken by many Chipileños of Italian descent and is the first language of many bilinguals in the community. Outsiders note an "accent" in Chipileño 
Spanish, which previous research has suggested may be due to influence from Veneto, at least in part in the form of prenuclear early peak alignment (Barnes \& Michnowicz 2013). Chipilo presents an interesting case for studies on language contact given that the two languages (Veneto and Spanish) have been in contact for over 130 years and both languages maintain a high level of prestige within the community. Previous work by Barnes (2009) has shown that speakers identify with Veneto and Veneto culture, are proud of their language and heritage, and often prefer speaking Veneto over Spanish. However, very little research has investigated the possible linguistic outcomes of Veneto-Spanish contact in Chipilo (see Barnes 2009, 2010). Therefore, not much is known about the intonation patterns of either bilingual Chipilo Spanish or Veneto, with only one study to date examining peak alignment strategies in spontaneous speech (Barnes \& Michnowicz 2013). As previous work has reported important differences in peak alignment between spontaneous and more controlled laboratory speech, with a lower rate of early prenuclear peaks in laboratory studies in some varieties (Face 2003), the present study will compare the results of a controlled experiment with previously reported results for spontaneous Chipilo Spanish (Barnes \& Michnowicz 2013). Based on previous research (Colantoni \& Gurlekian 2004, Colantoni 2011), any observed change in peak alignment could be due to contact effects from Veneto or from contact in general, as a type of simplification strategy on the part of bilingual speakers.

This paper is organized as follows. Section 2 provides background on the contact situation in Chipilo. Section 3 reviews previous studies on peak alignment in Spanish dialects, both monolingual and contact varieties. As Chipilo Spanish is in contact with Veneto, an Italic language, section 4 provides a general overview of intonation in Italian languages. Section 5 examines previous work on Chipilo Spanish and Veneto intonation in spontaneous speech, while section 6 outlines the research questions and the methodology for the present study. The results are given in section 7, with discussion and conclusions in section 8 .

\section{Community Background and bilingual Chipilo Spanish}

The Mexican government, following trends seen in other countries such as the United States and Argentina, had been considering European immigration from the middle of the $19^{\text {th }}$ century, but it was not successful until the 1880s. At that time, Mexico sought to encourage economic and population growth by recruiting European farmers and agricultural workers who could convert the many unused lands into productive resources. Initially, the government considered the recruitment of Spanish farmers, however, this idea was quickly dismissed due to the "sentimiento antiespañol de los criollos" (Zilli Manica 1981, p.13) as well as the recent expulsion of the Spanish from Mexico in 1827. France, with a colony having been previously established in Jicaltepec, Veracruz in 1857, was also dismissed due to the French intervention in 1862 (Zilli Manica 1981). Mexico therefore looked to northern Italy where potential colonists were anxious to find alternatives to the difficult economic times facing them. Sartor and Ursini (1983) note several reasons for the emigration from Italy, including the flooding of the Piave River, plagues, and a feeling of detachment from Italian nationality given that the Veneto region had only recently left the Austrian Empire and become part of Italy. Italy, at the time, was dealing with a struggling economy coupled with a growing population. Local Chipileño historian Zago notes that "la crisis radical del sistema agrario italiano que, junto con la elevada tasa del crecimiento poblacional, provocó el empobrecimiento de la clase campesina hasta llegar a extremos insostenibles" (2007, p.30). According to Baily (1999), Italian emigration was at its peak between 1876 and 1915, with nearly two thirds emigrating between 1901 and 1915. Emigration to Mexico was during the earliest period and the majority of immigrants were from the Northern regions, primarily Veneto.

In total, seven Italian colonies were established in Mexico between 1881 and 1882, of which Chipilo was the last. Chipilo was founded in October of 1882 by a fairly homogeneous group of approximately 560 Italian immigrants on the vacant haciendas of Chipiloc and Tenamaxtla, approximately 12 kilometers outside of the city of Puebla (MacKay 1992). The majority of the group came from the Veneto region of Northern Italy, specifically Segusino and the surrounding towns of Quero, Vas, Valdobbiadene, Feltre, Schievenin, Alano, Fener, Miane, Belluno, Colmirán, and Montebelluna, and most spoke a variety of Veneto. The initial homogeneity of the families living in Chipilo and the relative isolation from urban areas prevented rapid language shift and for many years, the immigrants lived and married amongst themselves (Zago 2007). Today, the population of Chipilo is estimated at 
approximately 5,000 inhabitants, of which approximately 3,000 are Veneto speakers. Despite the increasing dominance of the city of Puebla, many Chipileños speak Veneto on a daily basis as the regular means of communication. Everyone is bilingual in Spanish and Spanish is the language of the church and of education; however, Veneto remains the preferred language of the home and with family. Romani (1992) found that $99.2 \%$ of the population was bilingual, with very few monolingual Spanish speakers and no monolingual Veneto speakers. At the time of her study, which was conducted in 1984, the population of Chipilo was in its 5th generation and Veneto was the first language of the majority of the children of Italian descent. In more recent work, Barnes (2010) found that Veneto remains the primary home language in many households and that positive attitudes towards the use of Veneto within the community continue to contribute to the maintenance of this language. Interestingly, strong positive attitudes were also observed for younger generations, and, in some cases, the younger speakers appear to identify more with the Chipileño culture and language than older speakers. In spite of the positive attitudes surrounding the language, Veneto receives no institutional support, is frequently discouraged from use in the schools by non-Chipileño teachers, and has no accepted writing system. However, a strong sense of identity, positive attitudes, and dense social networks have led to its continued maintenance in the community (Barnes 2009, 2010, MacKay 1992, Romani 1992, Sartor and Ursini 1983, Zago 2007). This is further enhanced by direct contact with Segusino, one of the original towns of origin in Italy. There are often organized excursions that bring Italians to Chipilo and also Chipileños to the Veneto region of Italy. These excursions have reinforced the use of Veneto as the means of communication and have also established personal relationships and frequent communication between the two groups.

The language contact situation observed in Chipilo therefore provides a unique case of bilingualism given that many immigrant languages are lost within three generations and in the case of Chipilo, they are now in the seventh generation. Furthermore, Veneto and Spanish are typologically similar languages. The contact situation in Chipilo has not been widely studied until recently. Previous studies have primarily focused on questions of language maintenance and cultural heritage (Barnes 2010, MacKay 1992, Romani 1992, Sartor and Ursini, 1983). Little work, however, has been done on the linguistic outcomes of this contact. Previous work by Barnes (2009) found Veneto influence on bilingual Chipilo Spanish at the lexical, phonological, and syntactic levels. Regarding prosody, Barnes \& Michnowicz (2013) found similar patterns of early prenuclear peak alignment in broad focus declaratives in spontaneous Chipilo Spanish and Veneto for some speakers, a result they attribute to contact with Veneto. The intonational patterns in bilingual Chipilo Spanish, however, have not been thoroughly studied using methods from laboratory phonetics, allowing for comparability with other studies. As previous studies have found important differences in peak alignment between spontaneous and laboratory speech (Face 2003), the present study will allow for a more focused picture of prenuclear peak alignment patterns in Chipilo Spanish. Given the intense contact between Spanish and Veneto, and differing patterns of prenuclear peak alignment in broad focus declaratives between Spanish and Italian varieties (with Italian languages often showing early peak alignment) (Grice 1995, Ladd 1996), it is therefore possible that peak alignment in controlled bilingual Chipilo Spanish will also display effects of language contact.

\section{Peak alignment in Spanish}

\subsection{Monolingual varieties}

The current study examines peak alignment in broad focus declaratives. Most non-contact varieties of Spanish display a prenuclear $\mathrm{L}+>\mathrm{H}^{*}$ pattern, with the peak falling in the post-tonic syllable (late peak) (Face 2003, Hualde 2005, McGory \& Díaz-Campos 2002, O’Rourke 2004, see de-la-Mota, Butragüeño \& Prieto 2010 specifically for Mexico City, and Willis 2005 for Puebla, Mexico). In contrast, in nuclear, or final position, the F0 typically rises in the tonic syllable and the peak occurs there as well (early peak), rather than occurring in the post-tonic syllable. Face (1999) finds that nuclear peaks occur within the stressed syllable $98 \%$ of the time, thereby showing a clear distinction between nuclear and prenuclear peaks in Castilian Spanish, a pattern that exists in most other monolingual varieties studied to date. Most of the variation in peak alignment, then, occurs in prenuclear position. Figure 1 shows a stylized representation of late peak alignment (on the left), consistent with most non-contact 
varieties, and early peak alignment (on the right), found in many contact varieties. The zero line (0) in the middle of each graph represents the end of the stressed syllable. A peak to the right of the zero line occurs in the post-tonic syllable (late alignment), while a peak to the left occurs within the stressed syllable (early alignment).

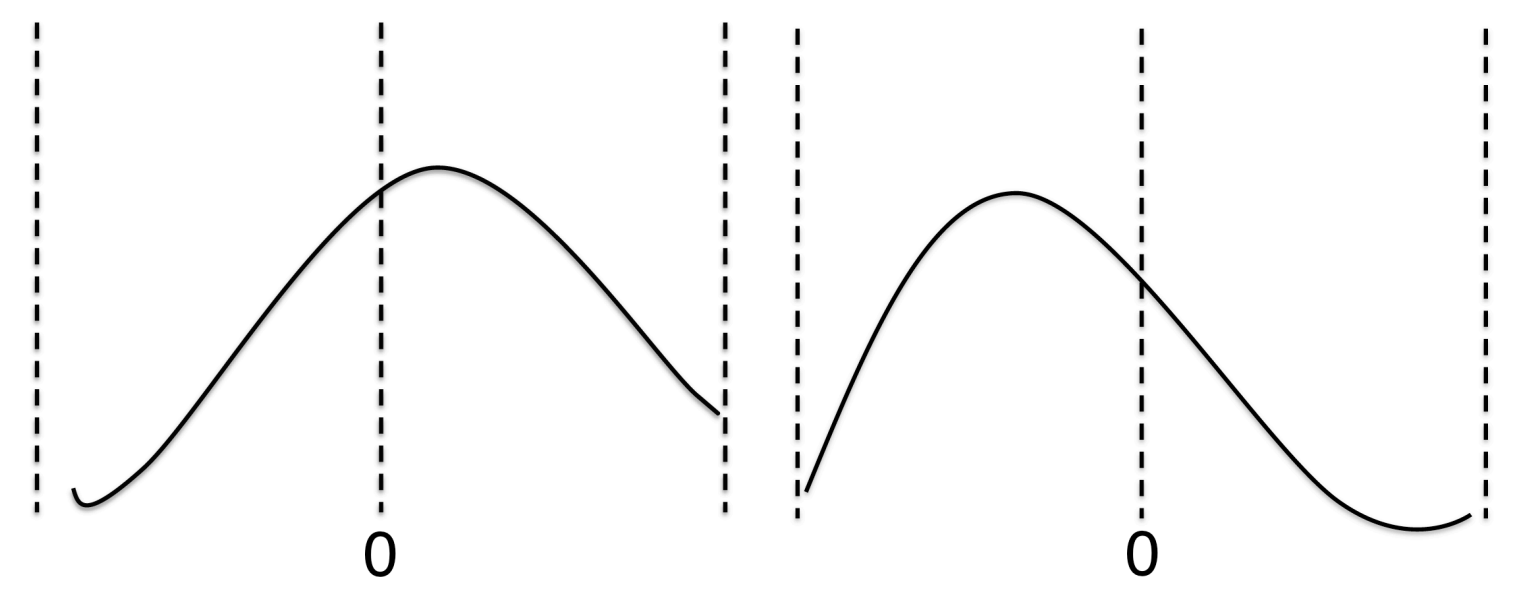

Figure 1. Stylized representations of late and early peak alignment. The 0 line is the end of the stressed syllable.

\subsection{Contact varieties}

Given that most of the variability in peak alignment has been found to occur in prenuclear position, this feature has been the focus of numerous studies on several contact varieties of Spanish, including Spanish in contact with English (Alvord 2010a b), German (Lleó, Rakow, \& Kehoe 2004), Basque (Elordieta 2003), Quechua (O’Rourke 2004, 2005), Yucatec Maya (Michnowicz and Barnes 2013) and in Buenos Aires, where Spanish was formerly in intense contact with Italian (Colantoni 2011, Colantoni \& Gurlekian 2004). These studies have demonstrated that language contact can have an effect on prenuclear peak alignment, with a higher rate of early peaks for Spanish speakers in frequent contact with Quechua (O'Rourke 2004), in Basque-Spanish (Elordieta 2003), Yucatan Spanish (Michnowicz \& Barnes 2013) and in Buenos Aires Spanish (Colantoni 2011, Colantoni \& Gurlekian 2004). Particularly relevant to the current study is the case of Buenos Aires Spanish where Colantoni \& Gurlekian (2004) and Colantoni (2011) argue that early peak alignment is due to transfer from Italian. Specifically, Colantoni \& Gurlekian (2004: 111) found 96\% early prenuclear peak alignment in Buenos Aires Spanish, with an $\mathrm{H}^{*}+\mathrm{L}$ alignment pattern accounting for $91 \%$ of the tokens. This pattern, with a high tone aligned with the stressed syllable followed by a falling tone, is also seen in the present data from Chipilo Spanish (see Figure 3 for the verb admira). As outlined below, early prenuclear peak alignment is reported for all Italian varieties (Grice 1995, Ladd 1996), a pattern also reflected in Buenos Aires Spanish. Not all contact varieties, however, show differences in peak alignment. For example, early peaks were not found in the case of Miami Cuban Spanish (Alvord 2010a). Alvord notes that with broad focus declaratives, Miami Cuban Spanish follows intonation patterns consistent with other non-contact varieties. Likewise, Colantoni (2011) also did not find early peaks in Northeastern Argentine Spanish in contact with Guarani. She therefore concludes that it is not a simplification process that results from language contact in general that results in a change of peak alignment, but rather the specific languages involved in the contact situation. Given that Chipileño Spanish is in contact with Veneto, a Northern Italian language, we predict that there will be a higher rate of early peaks in this dialect, as suggested for spontaneous speech (Barnes \& Michnowicz 2013). 


\section{Italian Intonation}

Given that in Chipilo Spanish is in contact with Veneto, it will be useful to review the literature on intonational patterns in Italian languages, to examine possible points of contact induced change. Veneto is a Northern Italian language and the variety spoken in Chipilo is of the Basso-Bellunese variety (MacKay 1992). The original immigrants to Chipilo were primarily from Segusino and nearby towns. As observed by Colantoni (2011), previous work on Italian intonation has focused on central and southern varieties of Italian, and very little has been reported specifically for northern varieties of Italian, such as Veneto. Furthermore, much of this research examines nuclear accents. As such, there is little work on prenuclear accents in Italian and even less known about prenuclear accents in Northern Italian varieties such as Veneto. D'Imperio (2002) classifies prenuclear accents in Italian as $\mathrm{H}^{*}$, a high tone aligned with the stressed syllable, although she notes that prenuclear peaks are still not realized as early as nuclear peaks. Likewise, Ladd (1996) and Grice (1995) have reported early peaks for all Italian varieties, although Colantoni (2011) notes that differences have been observed between central and southern varieties and northern varieties of Italian. Nuclear accents are consistently falling accents, with the peak aligned with the stressed syllable (Grice 1995, Ladd 1996). In sum, in Italian, prenuclear and nuclear accents both demonstrate early peak alignment, although differences in temporal alignment and the F0 contour may still serve to distinguish the two.

A further complication is that in Chipilo, Veneto has been in contact with Spanish for well over a hundred years and perhaps shows some evidence of convergence with Spanish with respect to peak alignment (see Barnes \& Michnowicz 2013). Additionally, there are no monolingual speakers of Veneto in Chipilo (Barnes 2009, 2010), and few if any monolinguals in Italy, where speakers are bilingual in Veneto and standard Italian, thus it is impossible to know exactly what the intonational patterns of the original Veneto immigrants to Chipilo might have been, given that this immigration occurred before the rise of standard Italian. Barnes \& Michnowicz (2013) report very similar peak alignment patterns in semi-spontaneous Chipilo Spanish and Veneto, a result which they attribute to convergence, assuming that previously Veneto displayed higher rates of early peaks, as suggested by the literature on Italian varieties.

\section{Prenuclear peak alignment in spontaneous Chipilo Spanish and Veneto}

Previous research has found that, in semi-spontaneous speech, Chipileño speakers show early prenuclear peak alignment with a range of 34\%-70\% early peaks and a mean of 53\% early peaks (Barnes \& Michnowicz 2013). This is higher than what has been reported for monolingual varieties; Face (2003, p.123) reports $25 \%$ early prenuclear peaks in spontaneous Castilian Spanish, and Rao (2005) found an average of 38\% early prenuclear peaks in spontaneous Central Mexican Spanish. This rate, however, is much lower than that found in spontaneous Buenos Aires Spanish, with between $80 \%-100 \%$ early prenuclear peak alignment (Colantoni 2011). As an initial point of comparison, previous research also examined semi-spontaneous speech in Chipilo Veneto and found a rate of $60 \%$ early prenuclear peaks, suggestive of convergence in peak alignment patterns between Chipilo Spanish and Veneto (Barnes \& Michnowicz 2013).

\section{Research Questions, goals, and methods}

\subsection{Research questions/goals}


Based on the findings of the previous research outlined above, we seek to address the following research questions: i) does bilingual Chipilo Spanish differ from monolingual Spanish with respect to prenuclear peak alignment?; ii) Will speakers demonstrate early prenuclear peak alignment as reported for Italian varieties?; and iii) Is there a difference between semi-spontaneous speech, as reported in Barnes \& Michnowicz (2013), and controlled, laboratory-type speech, with respect to prenuclear peak alignment in bilingual Chipilo Spanish?

Given that bilingual Chipilo Spanish displays increased rates of early peak alignment in semi-spontaneous speech (Barnes \& Michnowicz 2013), we predict that early prenuclear peaks will also be present in controlled speech. Face (2003) found that early prenuclear peak alignment is more common in spontaneous Castilian Spanish than in laboratory speech, where the focus, syllable structure, etc. are tightly controlled. While Face (2003) leads us to expect lower rates of early prenuclear peak alignment in controlled speech, Colantoni (2011) found different results in Buenos Aires Spanish, with the rate of early prenuclear peaks slightly lower in the semi-spontaneous speech, suggesting that in Buenos Aires, early peak alignment is simply the norm, regardless of the methodology employed. An interesting question, therefore, is whether bilingual Chipilo Spanish will show contextual variation in prenuclear peak alignment, as in Castilian Spanish, or will behave the same across task types, as in Buenos Aires Spanish. Thus a secondary goal of this paper is to contribute to our understanding of the role of methods (spontaneous vs. laboratory/read, speech) in studies of peak alignment. Based on the fact that, unlike Buenos Aires Spanish, early prenuclear peak alignment is not (virtually) categorical in spontaneous Chipilo Spanish, we predict that Chipilo Spanish will behave more like Castilian Spanish with respect to task (spontaneous vs. controlled). In other words, we predict a lower rate of early prenuclear peak alignment in the present controlled data than in the semi-spontaneous results of Barnes \& Michnowicz (2013), but a rate that is still greater than that reported for lab speech in non-contact varieties. Finally, given that both monolingual varieties of Spanish and Italian demonstrate early peak alignment in nuclear position, we predict the same pattern in the present data.

\subsection{Methodology}

\subsubsection{Participants}

For this study, the speech of 17 Veneto-Spanish bilinguals residing in Chipilo was recorded during the summer of 2013. There were 7 men and 10 women between the ages of 20 and 72 . All speakers are bilingual and all but one indicated Veneto as their L1. Participant GBY F-20 is of Chipileño descent but lived a significant period of time outside of Chipilo and noted Spanish as her L1. The remaining participants all indicated Veneto as their L1 and speak it on a daily basis with family and friends. After coding the data, 5 speakers were eliminated due to difficulties reading the sentences, including inaudible tokens or long pauses between tokens. These difficulties will be further addressed in the discussion. The following table provides a summary of the final 12 participants.

\begin{tabular}{lllll}
\hline Participant Code & Gender & Age & Date of birth & L1 \\
GBY F-20 & F & 20 & 1993 & Spanish \\
OLV F-20b & F & 20 & 1993 & Veneto \\
MSL F-22 & F & 22 & 1991 & Veneto \\
RNS F-22b & F & 22 & 1991 & Veneto \\
YZM F-26 & F & 26 & 1987 & Veneto \\
LZM F-30 & F & 30 & 1983 & Veneto \\
RSM F-34 & F & 34 & 1978 & Veneto \\
TTR F-72 & F & 72 & 1941 & Veneto \\
EZM M-31 & M & 31 & 1982 & Veneto \\
RPC M-40 & M & 40 & 1973 & Veneto \\
MMT M-32 & M & 32 & 1981 & Veneto \\
SLD M-60 & M & 60 & 1953 & Veneto \\
\hline
\end{tabular}




\section{Table 1. Participants}

\subsubsection{Materials}

Participants were asked to read 24 sentences taken from O'Rourke (2005). There were 12 target broad focus declarative sentences and 12 filler sentences. Each sentence was preceded by a question triggering the broad focus declarative, as shown in (1).

(1) ¿Qué pasa? Su madre admira la lana.

What's happening? Her mother admires the wool.

As noted by O'Rourke (2005), the sentences were controlled for voiced and voiceless segments, in that voiced consonants were frequently used to avoid breaks in pitch contour. Each subject NP, verb, and object NP contained only one stressed word. These sentences were also controlled for adjacency of stressed syllables to avoid tonal crowding.

Participants were recorded using a head-mounted microphone. Following previous research (Colantoni 2004, 2011, Michnowicz \& Barnes 2013, O'Rourke 2004, among others), the distance from the peak to the end of the stressed syllable was measured in Praat (Boersma \& Weenink 2012). The right boundary of the stressed syllable was considered the zero line; if the peak occurred to the left of this line (i.e. within the stressed syllable), it received a negative value and was considered early; if the peak occurred to the right of the zero line, the measurement was positive and the peak was considered late (i.e. in the post-tonic) syllable. A Praat script was used to extract the measurements to a spreadsheet (Kendall 2009), and data was analyzed quantitatively using R (R Development Core Team). A sample measurement is shown in Figure 2.

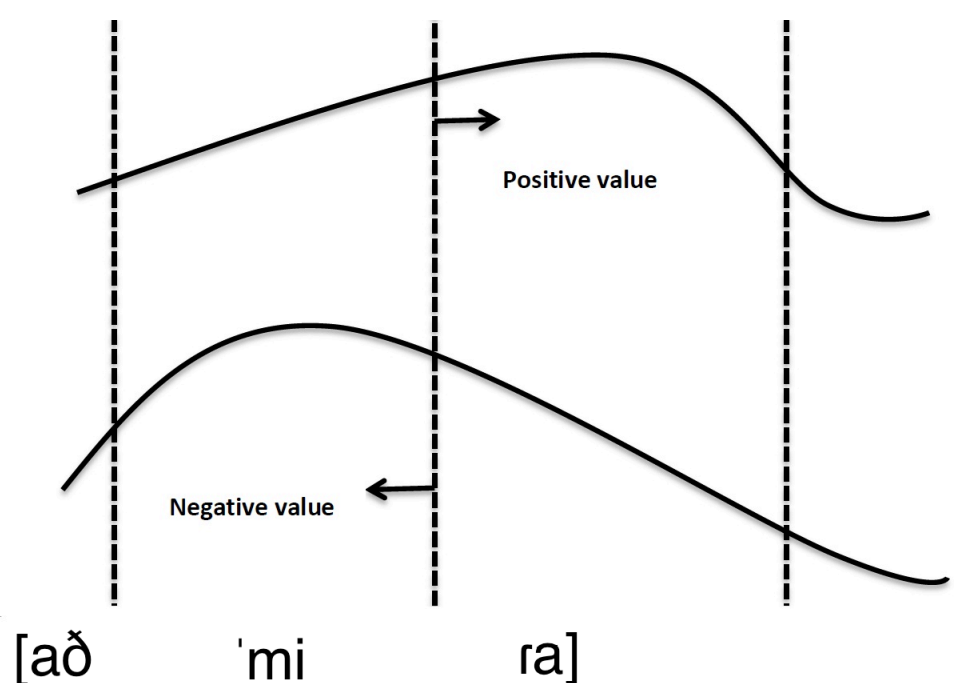

Figure 2. Example of peak measurement. Adapted from O’Rourke (2004, p.327).

A total of 233 tokens were analyzed (81 subjects; 79 verbs; 73 objects), with a minimum of 12 tokens per speaker. A sample phrase can be seen in Figure 3, spoken by a 22 year-old woman (MSL F-22). A late peak is evident for the subject (madre), while early peaks are visible for the verb (admira) and the object (lana). 


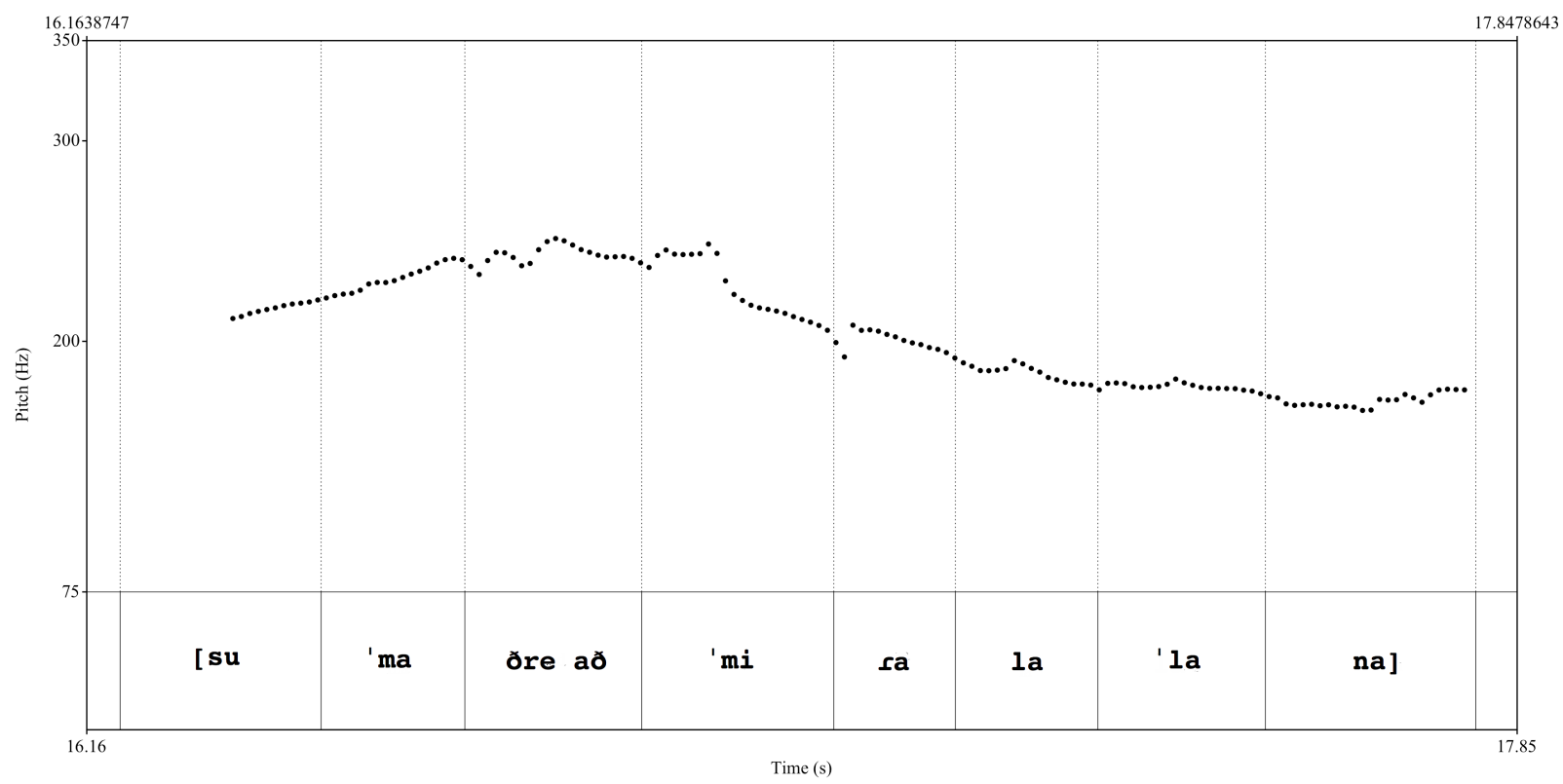

Figure 3. Sample phrase showing peak alignment; 22 year-old woman (MSL F-22)

\section{Results}

In the controlled data examined here, an overall rate of $24 \%$ prenuclear peaks occurred within the stressed syllable (early peaks). A majority of these occurred with the verb in second position (32\% early peaks), compared with only $6 \%$ early peaks for subjects in first position. Objects, appearing in nuclear position, largely behaved as expected, with $86 \%$ early peaks. Figure 4 shows the overall peak alignment by word type. In the boxplots, the dark line in the box represents the median peak alignment value. Values to the right of the 0.0 line on the $\mathrm{X}$-axis indicate late peak alignment; to the left are early peaks. Mixed effects linear regression analyses (speaker as a random factor) fit to the data using lme in $\mathrm{R}$ found significant overall differences between all three word types $(\mathrm{p}<0.000)$. No social factors (age or gender) were found to be significant in the overall data, and there were no significant interactions. 


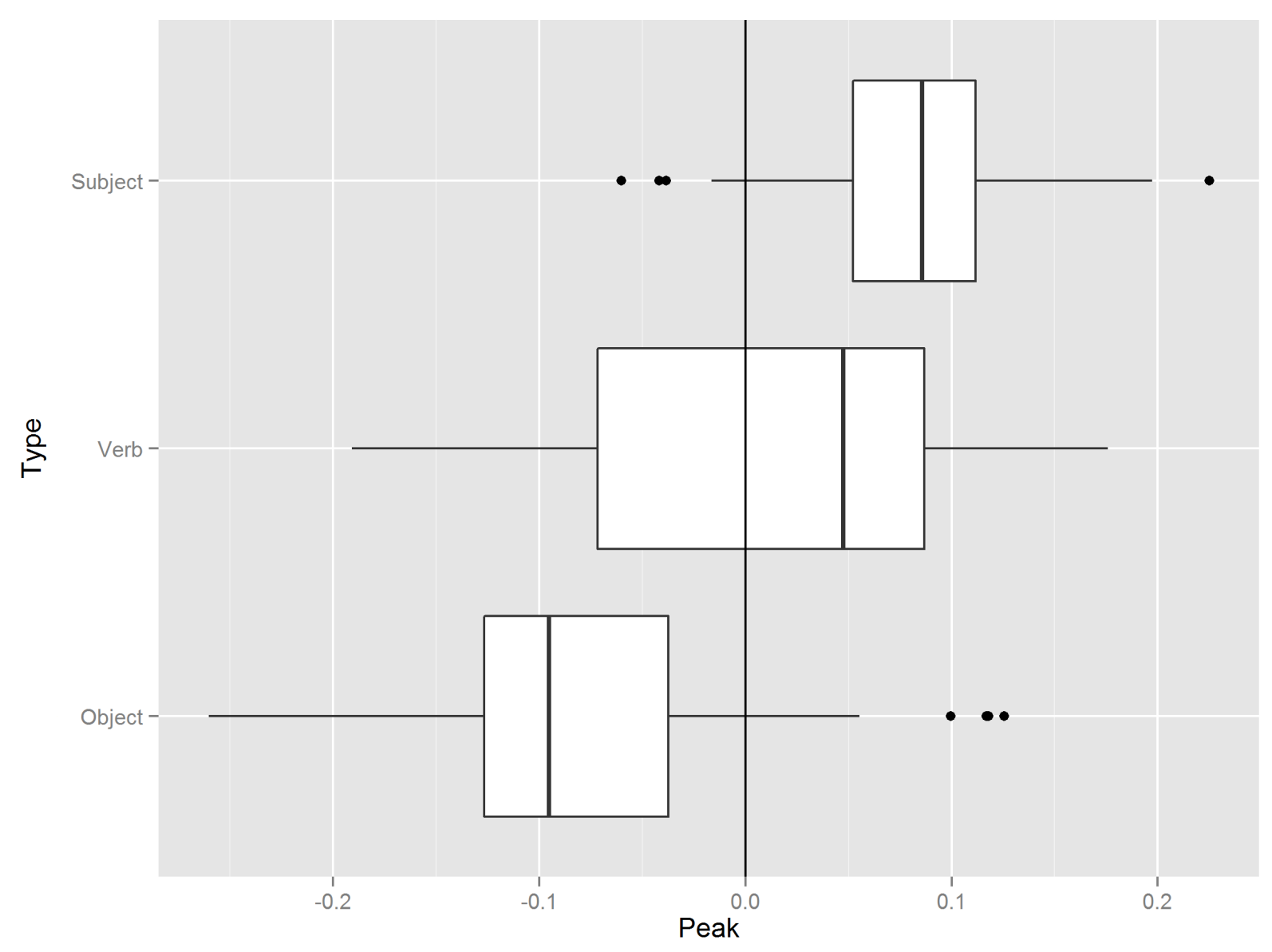

Figure 4. Peak alignment by Word Type. Alignment to the left of the 0.0 line on the $x$-axis is an early peak.

\begin{tabular}{lllll}
\hline Variable & Estimate & Std. Error & t value & Significance \\
\hline Subject $\sim$ Verb & 0.067 & 0.012 & 5.39 & $* * *$ \\
Subject $\sim$ Object & 0.176 & 0.031 & 5.717 & $* * *$ \\
Verb Object & 0.097 & 0.012 & -7.665 & $* * *$ \\
Age - Younger & -0.003 & 0.032 & -0.104 & NS \\
Gender - Male & -0.011 & 0.035 & -0.318 & NS \\
Speaker (Random) & Std.Dev. 0.02 & & & \\
\hline Number of observations: 233 & & & \\
\hline
\end{tabular}

Table 2. Regression results for peak alignment. Signif. codes: 0 ‘***, 0.001 ‘**, 0.01 ‘*, 0.05

As predicted by previous studies that found increased variation in peak alignment in spontaneous speech compared to controlled speech (Face 2003), this rate of $24 \%$ prenuclear early peaks is substantially less than the $54 \%$ early peaks found by Barnes \& Michnowicz (2013) for spontaneous Chipilo Spanish. This result, however, is compatible with a contact explanation, given that the rate of early peaks in controlled bilingual Chipilo Spanish is virtually identical to the $25 \%$ early peaks found for spontaneous Castilian Spanish (Face 2003). In other words, Chipilo Spanish peak alignment behaves, at its most controlled when it should display the lowest rate of early prenuclear peak alignment, like monolingual Castilian Spanish in a spontaneous setting, when it should evince its highest rate of early prenuclear peaks. It is important to note, however, that Chipilo Spanish demonstrates a much lower rate of early prenuclear peaks than the $80-100 \%$ found in semi-spontaneous Buenos Aires Spanish (Colantoni 
2011). In this way, Chipilo Spanish overall appears to lie at a midpoint between monolingual Castilian Spanish and contact-influenced Buenos Aires Spanish. In particular, speakers in the present study demonstrate mixed patterns of peak alignment, similar to that found by O'Rourke (2005) for Spanish-Quechua bilinguals.

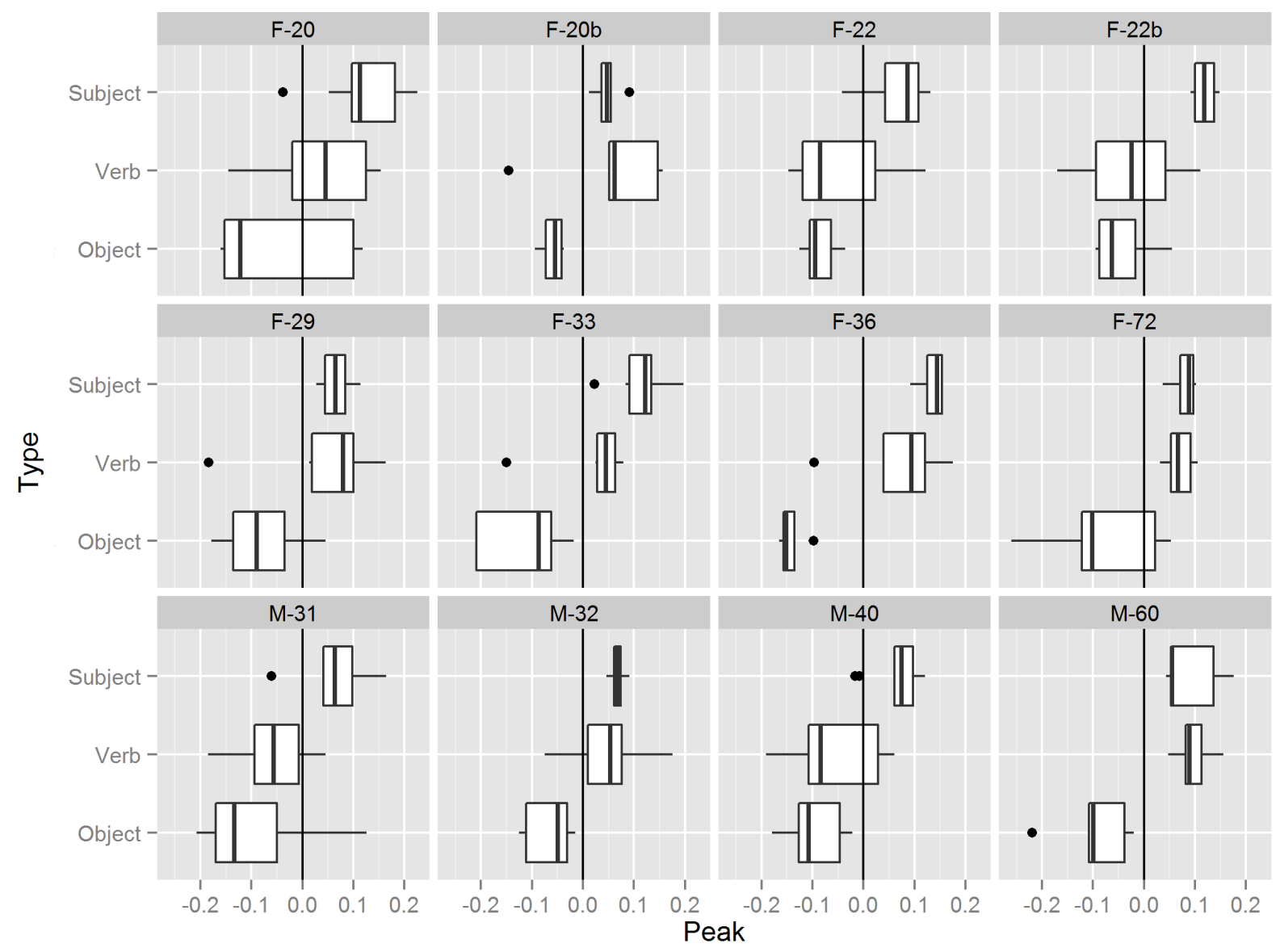

Figure 5. Word Type by Speaker. Speaker codes indicate gender and age (e.g., F-20 is a 20 year old female).

As seen in Figure 5, all speakers consistently produced late peaks for subjects and early peaks for objects, in agreement with reports of non-contact Spanish. Verbs, however, showed more variation. Of the twelve speakers analyzed, seven show alignment patterns consistent with non-contact varieties, with late peaks in prenuclear position (subjects and verbs), and early in nuclear position (objects) (F-20b, F-29, F-33, F-36, F-72, M-32, M-60). The remaining five speakers, however, show patterns for verbs that align with previous reports of contact Spanish (early peak alignment) (F-20, F-22, F-22b, M-31, M-40). Examining these five speakers in more detail reveals several interesting patterns. 


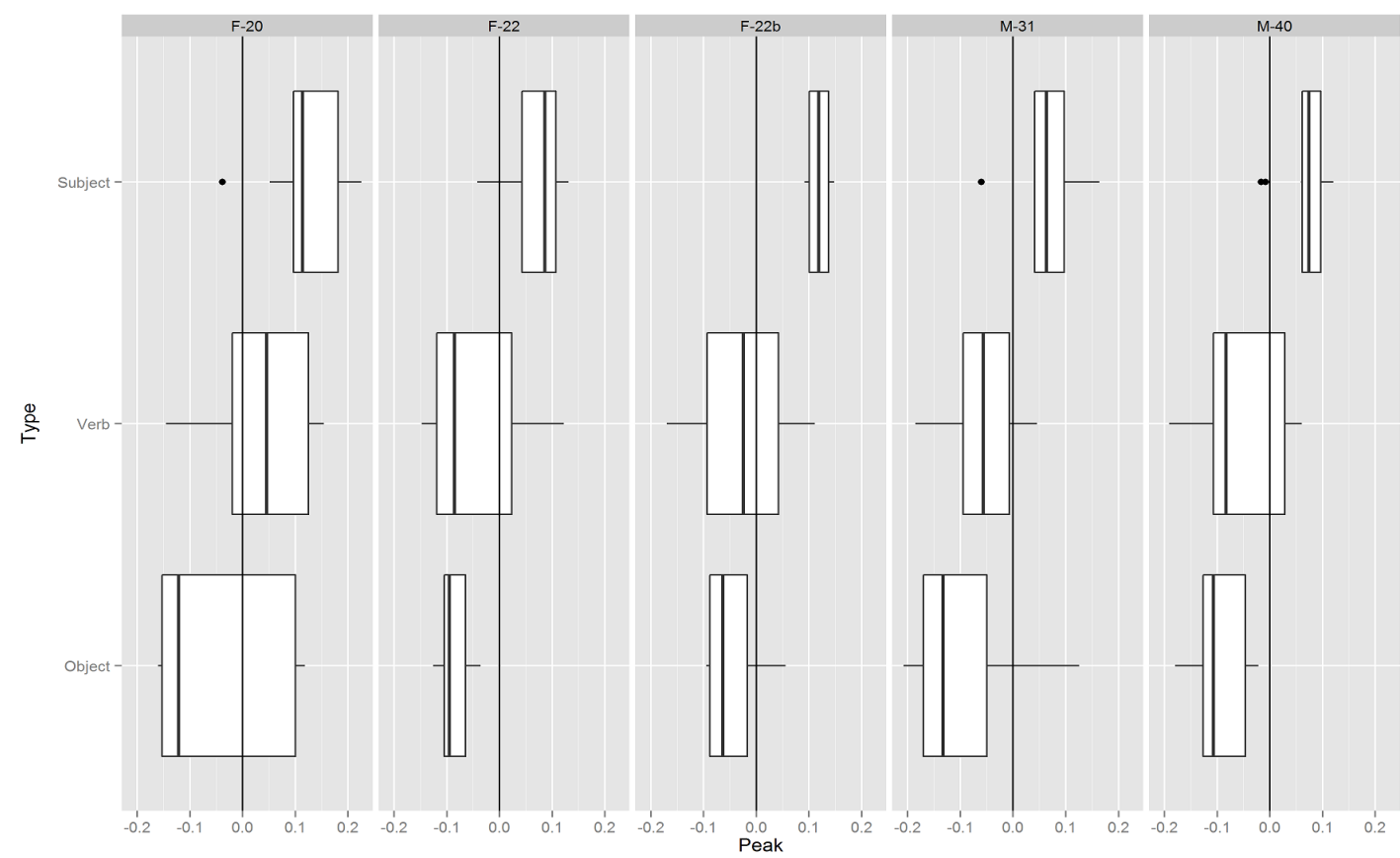

Figure 6. Peak alignment by Word Type for the five speakers showing early alignment on Verbs.

First, one-way ANOVA analyses revealed a significant main effect of Word Type for all speakers except M-31, as seen in Table 3 .

\begin{tabular}{lll}
\hline Speaker & F & Significance \\
\hline F-20 & $\mathrm{F}(2,24)=5.697$ & $\mathrm{p}<0.01$ \\
$\mathrm{~F}-22$ & $\mathrm{~F}(2,21)=11$ & $\mathrm{p}<0.01$ \\
$\mathrm{~F}-22 \mathrm{~b}$ & $\mathrm{~F}(2,9)=4.778$ & $\mathrm{p}<0.05$ \\
M-31 & $\mathrm{F}(2,11)=2.613$ & $\mathrm{NS}$ \\
M-40 & $\mathrm{F}(2,25)=15.26$ & $\mathrm{p}<0.00$ \\
\hline
\end{tabular}

Table 3. Results of one-way ANOVAs on Word Type.

In order to determine the specific distinctions in peak alignment across word types, a Tukey post-hoc test was conducted for each speaker that showed significant differences, the results of which are found in Table 4. 


\begin{tabular}{llll}
\hline & S - V & S - O & V - O \\
\hline F-20 & NS & $*$ & NS \\
F-22 & $*$ & $* *$ & NS \\
F-22b & NS & $*$ & NS \\
M-40 & $* *$ & $* * *$ & NS \\
\hline
\end{tabular}

Table 4. Results of Tukey post-hoc tests for Word Type. Signif. codes: 0 ‘***, 0.001 ‘**, 0.01 ‘*, 0.05

The post-hoc tests revealed that the differences in peak alignment between Subject-Verb were significant for only two of the four speakers (F-22 and M-40). All speakers demonstrated significant alignment differences between Subjects and Objects. Importantly, none of these four speakers produced significantly different peak alignment patterns between Verbs and Objects. When we also take into account speaker M-31, who showed no significant differences at all across word types, for all five speakers that demonstrated contact-like patterns of peak alignment, verbs behaved much the same as nuclear peaks. These results for bilingual Chipilo Spanish are similar to O'Rourke's (2005) findings on bilingual Cuzco Spanish, and largely correspond to her Pattern C category, in which the "mean of the prenuclear verb peaks appear within the stressed syllable", while the subject aligns with the posttonic syllable (80). This leads O'Rourke (2005, p.80) to hypothesize that peak alignment for subjects may be more resistant to contact-induced change than verbs, a finding corroborated by the present results ${ }^{1}$. She notes that Patterns $\mathrm{C}$ and D (in which both subjects and verbs demonstrate early peak alignment, a pattern not seen in the present bilingual Chipilo data) appear to be due to direct or indirect contact with Quechua (pp. 85-86). Importantly, at the same time, the demonstrated alignment patterns in Cuzco Spanish do not seem to correlate directly with the level of knowledge of Quechua (p. 85). Likewise in the present data, there does not seem to be a clear relationship between amount of Veneto used by the speakers and patterns of peak alignment, although as noted previously all of the speakers are fluent speakers of both languages. For example, we observe that the only speaker to indicate Spanish as her L1 (F-20) patterns with the other young women, who indicated Veneto as their L1. At the same time, the two male speakers in Table 3 (M31 and M40) both use Veneto as their primary language when speaking with family and friends in the Chipilo community and both are very active in Veneto cultural events. However, both work outside of the community, in Puebla and Cholula respectively, and therefore use Spanish as the main language of the

${ }^{1}$ Another possibility, pointed out by two of the anonymous reviewers, is that it is not so much subjects that are more resistant to change, but that the main factor may be position in the phrase. Therefore, first position in the phrase may show different patterns than second position, regardless of their grammatical categories. Given that all of the target phrases in this study (and in O'Rourke 2005) were SVO, we cannot address this possibility with our data, but this is a possibility that could easily be tested in future research. An additional possibility is the presence of a boundary tone after the subject in some of the phrases. D'Imperio et al. (2005) found that Spanish often exhibits a boundary tone between the subject and verb, giving a (S)(VO) structure. As pointed out by an anonymous reviewer, the presence of a boundary in this position may affect the F0 contour. In fact, it is not uncommon to find a boundary between subject and verb in our data, which would be classified as level 2 (BI2) or level 3 (BI3), following Sp_Tobi classifications. For examples, see: http://prosodia.upf.edu/sp tobi/en/labeling system/prosodic phrasing/prosodic phrasing.html 
workplace. Both are university educated and very attuned to questions of language maintenance and the importance of retaining Veneto in the community, as opposed to some of the other speakers who are not as metalinguistically aware. As such, these two male speakers may demonstrate a stronger desire to distinguish themselves from the mainstream Mexican culture that they interact with on a daily basis by using a more Veneto-influenced speech (see Barnes 2010). This will be further discussed in the next section.

Importantly, of the five speakers that show patterns of early peak alignment, three are young women (F-20, F22, F-22b). Although gender was not a significant predictor overall in the present controlled data, this finding supports the result in Barnes \& Michnowicz (2013) that in spontaneous speech, younger women tended to produce increased early peaks compared to other groups.

\section{Discussion}

We now return to the research questions outlined in section 6.1. First, does bilingual Chipilo Spanish differ from monolingual Spanish with respect to prenuclear peak alignment? Our results show that at least some speakers of bilingual Chipilo Spanish show alignment patterns that differ from those found in most monolingual varieties. In the present data, five of the twelve speakers analyzed showed increased rates of early peak alignment on Verbs in second position. None of those speakers showed significant differences between Verbs (prenuclear position) and Objects (nuclear position), demonstrating that, for this subgroup, these two categories behaved identically with respect to early peak alignment. Importantly, this result suggests possible convergence with Veneto, as Italian languages in general also display early peak alignment for both prenuclear and nuclear accents (Grice 1995; Ladd 1996). Simonet (2011) asserts that intonational convergence can occur in situations of societal bilingualism, as he finds in the case of Catalan-Spanish early bilinguals. At an individual level, the author notes a tendency to transfer the intonational patterns of the native language into the non-native language. This transfer of peak alignment strategies is also supposed for Buenos Aires Spanish (Colantoni \& Gurlekian, 2004; Colantoni, 2011). In Chipilo, however, results do not suggest direct transfer from Veneto to Spanish but rather convergence between the two languages. Michnowicz \& Barnes (2013) found that spoken Chipilo Veneto and Spanish demonstrate very similar alignment patterns $(60 \%$ and $53 \%$ early peaks respectively), with Veneto also displaying early peak alignment, although not as categorically as may be expected for some other Italian varieties. Given that Chipilo Veneto has been in close contact with Spanish for well over a hundred years, it is plausible that this particular variety of Veneto has converged with Spanish with respect to peak alignment, thereby resulting in both a unique variety of contact Veneto as well as contact Spanish. (see Barnes \& Michnowicz 2013). Unfortunately, there is no way to further test this first possibility, given that the monolingual variety of Veneto that the first immigrants to Chipilo spoke no longer exists. Likewise, as previously mentioned, there are few if any monolingual Veneto speakers in Italy, where the population is bilingual in Standard Italian. Future study should examine this variety in Italy, which may shed light on questions of intonational convergence in typologically similar languages.

While the present results are suggestive of intonational convergence, the fact that not all of the speakers demonstrated early alignment of prenuclear peaks, in spite of being bilingual Veneto-Spanish speakers, indicates that there may be other factors at work here. The question remains of why younger women seem to demonstrate more early peaks, in both controlled and spontaneous data (although as noted above, some men also show the same patterns). One possibility proposed by Barnes \& Michnowicz (2013) is that supra-segmental features, including peak alignment, are used as identity markers for some speakers. Speakers may be enhancing their status as members of the in-group of Chipileños and distinguishing themselves from the mainstream Mexican identity (Barnes 2009, 2010). Previous research has found that Chipileños often identify themselves not as only Mexican or Italian, but more as Chipileño. Data from a sociolinguistic questionnaire showed that many Chipileños rated Spanish less favorably than Veneto and identified less with the national Mexican culture, particularly women and the younger speakers (Barnes, 2010). Romani (1992) also found that the youngest participants in her study, regardless of L1, showed the most confidence in their expression ability in both Spanish and Veneto. She interpreted this to mean that the younger generations have positive attitudes towards both the local Chipileño culture, in addition to also identifying with national Mexican culture. Given the proximity and constant growth of the major city of Puebla, there are increased educational and employment opportunities where Spanish is the sole language used. As bilingual 
Chipileños come into increased frequent contact with Spanish, they may be enhancing their in-group status by using Veneto-influenced features in their Spanish. This ethnolinguistic identity may be reflected in the peak alignment of these speakers as they attehmp to distinguish themselves from the out-group. Additionally, yearly excursions between Italy and Mexico have strengthened relationships between these two communities, thereby reinforcing the Chipileño, or Veneto, identity in the community. In the present study, four of the five speakers who demonstrate higher rates of early peaks use Spanish almost daily at the workplace. Given their increased interaction with Spanish, the use of early peaks and a more Veneto-influenced Spanish may allow them to highlight their identity as Chipileños in a mainstream Mexican environment. O'Rourke (2012) found a similar trend in Peru where early peak alignment appeared to be connected to questions of identity.

With regards to the analysis of peak alignment in semi-spontaneous and laboratory speech, we found a difference between the present controlled data and the semi-spontaneous data reported in previous work. As found for other varieties (e.g., Castilian Spanish (Face 2003)), a comparison of the present results with the naturalistic speech in Barnes \& Michnowicz (2013) shows a lower rate of early prenuclear peak alignment in more controlled speech. When compared with the higher rate for spontaneous Chipilo Spanish (Barnes \& Michnowicz 2013), this variety patterns with Castilian Spanish in showing an effect of task (controlled vs. spontaneous speech), and differs from Buenos Aires Spanish, which showed near categorical early peaks in both types of task (Colantoni \& Gurlekian 2004, Colantoni 2011). This discrepancy may be the result of the different contact situations in Chipilo and Buenos Aires. While both communities are or were in contact with varieties of Italian, Veneto is a northern Italian language, as opposed to southern Italian, and less is known about these varieties. It is possible that Northern Italian varieties do not demonstrate as many early peaks as other varieties of Italian (Grice 1995, Ladd 1996). Furthermore, the influence of Italian on the Spanish of Buenos Aires, the national capital and a major metropolitan area, was more wide-spread and, in spite of the lack of actual direct contact between the two languages currently, the previous contact environment resulted in transfer of intonational patterns from Italian to Buenos Aires Spanish. In contrast, Veneto and Spanish are still in contact in Chipilo, but the much smaller number of immigrants, as well as the sociohistorical context of Chipilo, where Veneto was confined to the community and did not influence the wider prestige varieties in nearby Puebla, may have led to differing results in Chipilo vs. Buenos Aires. As mentioned, Chipilo Spanish and Veneto show evidence of convergence, rather than of direct transfer.

Given that the current results, along with those of Colantoni (2011), show early peaks in both controlled and semi-spontaneous speech, the need to include semi-spontaneous speech in research on intonation is evident if we are to understand how intonation patterns in everyday, running speech. Furthermore, the use of semi-spontaneous speech allows for the inclusion of more speakers, especially when investigating rural communities in which not all speakers are highly literate in the language(s) being studied. While many laboratory studies enlist university students or other highly literate subjects, we encountered several problems with a reading task in the course of the present investigation. As noted, several speakers had to be removed from the analysis, as the controlled speech task proved difficult for them. The requirements of the task (number of stressed syllables, voiced segments, tonal spacing, etc.) resulted in sentences that were not very natural (although useful for comparison across studies). Given the nature of the task, several speakers struggled to read the sentences without pausing, hesitating, or re-reading parts of them. This is also why the present study does not include a comparison with controlled Veneto speech. As mentioned, Veneto is not normally a written language in Chipilo, and it lacks a standard orthography. Attempting a reading task in a language that is primarily oral would have been impossible.

\section{Conclusion}

This study analyzed early peak alignment in laboratory speech of Veneto-Spanish bilinguals. It provides additional evidence to support a contact hypothesis for early peak alignment. Our results are consistent with those of previous research (Colantoni \& Gurlekian (2004) and Colantoni (2011) in Argentina, Simonet (2011) in Majorca, and O'Rourke (2005) in Peru) in that Veneto appears to have influenced Chipileño Spanish with respect to peak alignment, at least for some speakers. Given that these speakers do not exhibit high overall rates of early peak alignment as compared to Buenos Aires Spanish, it would seem that the prolonged language contact and intense 
bilingualism observed in Chipilo has resulted in convergence with respect to peak alignment, rather than the direct transfer of an Italian pattern, as is indicated for Buenos Aires. Additionally, increased employment and education opportunities in nearby Puebla have also enhanced contact with Spanish and created more contexts in which Spanish is the primary language spoken throughout the day. Given that not all speakers demonstrate the same degree of early peaks, it may be that early peaks are associated with an individual's identity. Those speakers that wish to distinguish themselves more from mainstream Mexican society may be more likely to display early peaks. Caution is still needed given the lack of data from Veneto and a control group from monolingual Mexican Spanish speakers Regarding the comparison of controlled, laboratory speech and spontaneous speech, as noted above, the rate of early peak alignment in controlled bilingual Chipilo Spanish is comparable to naturalistic Castilian Spanish. This result in the expected direction for bilingual Chipilo Spanish further confirms the spontaneous results in Barnes \& Michnowicz (2013), and suggests that an increased focus on spontaneous speech in intonation research can both confirm patterns found in laboratory speech, as well as provide a more realistic picture of how speakers utilize different intonational features in their everyday speech. Furthermore, the fact that some younger speakers demonstrate early peaks more frequently may be due to efforts to strengthen their Chipileño identity and separate themselves from the out-group. In sum, this paper demonstrates a need to include both controlled speech and semispontaneous data in studies of peak alignment and it also provides further evidence that it is not contact in general that leads to early peak alignment but rather the languages involved in the contact situation.

Appendix

1. ¿Qué pasaba? Amalia podaba los árboles.

2. ¿Quién estudiaba matemáticas? Josefina estudiaba matemáticas.

3. ¿Qué pasa? Su madre admira la lana.

4. ¿Julio vivía en el sótano? No. Victor vivía en el sótano.

5. ¿Quién era médico? Su primo era médico.

6. ¿Qué pasará? Su hermana retirará la demanda.

7. ¿Qué pasa? El niño añade los rábanos.

8. ¿Qué hacía su primo? Su primo era médico.

9. ¿Qué pasará? Su familia mandará los violines.

10. ¿Qué pasaba? José salía temprano.

11. ¿Marleni salía temprano? No. José salía temprano.

12. ¿Qué pasará? Bernardo venderá los mangos.

13. ¿El charangüísta toca magnífico? No. El guitarrista toca magnífico.

14. ¿Qué pasa? Yolanda domina el castellano.

15. ¿Cuándo venía tu tío? Mi tío venía los sábados.

16. ¿Qué pasaba? El criminal llevaba el ídolo. 
17. ¿Quién salía temprano? José salía temprano.

18. ¿Qué pasará? El albañil moverá los barriles.

19. ¿Qué pasa? El vándalo agarra los baldes.

20. ¿Dónde vivía Victor? Victor vivía en el sótano.

21. ¿Su hija comía manzanas? Sí. Su hija comía manzanas.

22. ¿Qué pasaba? El águila guardaba el nido.

23. ¿Qué pasaba? La víbora devoraba los animales.

24. ¿Tomasa estudiaba matemáticas? No. Josefina estudiaba matemáticas.

\section{References}

Alvord, Scott M. 2006. Spanish intonation in contact: The case of Miami Spanish bilinguals. Doctoral Dissertation, University of Minnesota.

Alvord, Scott M. 2010a. Miami Cuban Spanish Declarative Intonation. Studies in Hispanic and Lusophone Linguistics 3(1), 3-39.

Alvord, Scott M. 2010b. Variation in Miami Cuban Spanish Interrogative Intonation. Hispania. 93(2), 234-252.

Avesani, Cinzia. 1990. A contribution to the synthesis of Italian intonation. Proceedings of the international conference of spoken language processing, 833-836. Kobe.

Baily, Samuel L. 1999. Immigrants in the Lands of Promise: Italians in Buenos Aires and New York City, 18701914. Ithaca: Cornell University Press.

Barnes, Hilary. 2009. A sociolinguistic study of sustained Veneto-Spanish bilingualism in Chipilo, Mexico. Doctoral Dissertation, The Pennsylvania State University.

Barnes, Hilary. 2010. Social Motivations for Sustained Bilingualism in an Italo-Mexican Community. In Claudia Borgonovo, Manuel Español-Echevarría \& Philippe Prévost (eds.), Selected Proceedings of the 12th Hispanic Linguistics Symposium. 122-135, Somerville, MA: Cascadilla Proceedings Project.

Barnes, Hilary \& Jim Michnowicz. 2013. Peak alignment in semi-spontaneous bilingual Chipilo Spanish. In Ana M Carvalho \& Sara Beaudrie (eds.), Selected Proceedings of the $6^{\text {th }}$ Workshop on Spanish Sociolinguistics, 109122, Somerville, MA: Cascadilla Proceedings Project.

Bergmann, Anouschka. 2005. Accent and information structure in Veneto Italian. Actes des VIIIemes RJC ED268 'Langage et langues', Paris III, 21 mai 2005.

Boersma, Paul \& David Weenink. 2012. Praat: doing phonetics by computer [Computer program]. Version 5.3.19, retrieved from http://www.praat.org/

Borràs-Comes, Joan \& Rafèu Sichel-Bazin. Sp_Tobi Training Materials. Retrieved from http://prosodia.upf.edu/sp_tobi/en/labeling_system/prosodic_phrasing/prosodic_phrasing.html

Colantoni, Laura. 2011. Broad-focus declaratives in Argentine Spanish contact and non-contact varieties. In Christoph Gabriel \& Conxita Lleó (eds), Intonational phrasing at the interfaces: cross-linguistic and bilingual studies in Romance and Germanic, 183-212, Amsterdam: John Benjamins.

Colantoni, Laura \& Jorge Gurlekian. 2004. Convergence and intonation: Historical evidence from Buenos Aires Spanish, Bilingualism: Language and Cognition 7(2), 107-119.

de-la-Mota, Carme, Pedro M. Butragueño \& Pilar Prieto. 2010. Mexican Spanish Intonation. In Pilar Prieto \& Paolo Roseano (eds.), Transcription of Intonation of the Spanish Language, 319-350, Munich: Lincom Europa.

D'Imperio, Mariapaola. 2002. Italian intonation: An overview and some questions. Probus 14, 37-69.

Elordieta, Gorka. 2003. The Spanish intonation of speakers of a Basque pitch-accent dialect. Catalan Journal of Linguistics 2, 67-95.

Face, Timothy L. 1999. A phonological analysis of rising pitch in Castilian Spanish. Hispanic Linguistics 11, 37-49.

Face, Timothy L. 2001. Focus and early peak alignment in Spanish intonation. Probus 13, 223-246.

Face, Timothy L. 2002. Intonational marking of contrastive focus in Madrid Spanish. Munich: Lincom Europa. 
Face, Timothy L. 2003. Intonation in Spanish declaratives: differences between lab speech and spontaneous speech. Catalan Journal of Linguistics 2, 115-131.

Grice, Martine. 1995. The intonation of interrogation of Palermo Italian. Tubingen: Niermeyer.

Grice, Martine, Mariapaola D'Imperio, Michelina Savino \& Cenzia Avesani. 2005. Strategies for intonation labeling across varieties of Italian. In S-A. Jun (ed.), Prosodic Typology, 362-389, Oxford: OUP.

Hualde, José Ignacio. 2002. Intonation in Spanish and the other Ibero-Romance languages: overview and status quaestionis. In Caroline Wiltshire \& Joaquim Camps (eds.), Romance Philology and Variation, 101-115, Philadelphia: John Benjamins.

Hualde, José Ignacio. 2005. The sounds of Spanish. Cambridge UK: Cambridge University Press.

Kendall, Tyler. 2009. parse_textgrid [Computer program]. Retrieved from http://ncslaap.lib.ncsu.edu/tools/scripts/parse_textgrid_transcript.praat

Ladd, Robert. 1996. Intonational phonology. Cambridge: Cambridge University Press.

Lleó, Conxita, Martin Rakow \& Margaret Kehoe. 2004. Acquisition of language specific pitch accent by Spanish and German monolingual and bilingual children. In Timothy L. Face (ed.), Laboratory Approaches to Spanish Phonology, 3-27, The Hague: Mouton.

MacKay, Carolyn. 1992. Language maintenance in Chipilo: a Veneto dialect in Mexico. International Journal of Social Language 96, 129-145.

Michnowicz, Jim \& Hilary Barnes. 2013. A sociolinguistic analysis of prenuclear peak alignment in Yucatan Spanish. In Chad Howe, Sarah E. Blackwell \& Margaret Lubbers Quesada (eds.), Selected Proceedings of the 15th Hispanic Linguistics Symposium, 221-235, Somerville, MA: Cascadilla Proceedings Project.

McGory, Julia Tevis \& Manuel Díaz-Campo. 2002. Declarative intonation patterns in multiple varieties of Spanish. In James F. Lee, Kimberly L. Geeslin \& J. Clancy Clements (eds.), Structure, Meaning, and Acquisition in Spanish, 73-92, Somerville, MA: Cascadilla Press.

O'Rourke, Erin. 2004. Peak placement in Peruvian Spanish. In Julia Auger, J. Clancy Clements \& Barbara Vance (eds.), Contemporary Approaches to Romance Linguistics: Selected papers from the 33rd Linguistic Symposium on Romance Languages (LSRL), 321-341, Amsterdam: John Benjamins.

O'Rourke, Erin. 2005. Intonation and language contact: A case study of two varieties of Peruvian Spanish. Doctoral Dissertation, University of Illinois at Urbana Champaign.

O’Rourke, Erin. 2012. Intonation in Spanish. In José Ignacio Hualde, Antxon Olarrea \& Erin O'Rourke (eds.), Handbook of Hispanic Linguistics, 173-191. Malden, MA \& Oxford: Wiley-Blackwell.

Prieto, Pilar \& Francisco Torreira. 2006. The segmental anchoring hypothesis revisited: Syllable structure and speech rate effects on peak timing in Spanish. Journal of Phonetics 35, 473-500.

R Development Core Team. 2011. R: A language and environment for statistical computing. http://www.Rproject.org

Rao, Rajiv. 2005. The phonetics, phrasing, and pragmatics of spontaneous speech intonation in Mexican Spanish. Presentation at the Phonetics and Phonology in Iberia (PaPI) conference, Universitat Autónoma de Barcelona, June 2005. $\quad$ Retrieved December $15, \quad 2011$ from http://webs2002.uab.es/filologiacatalana/papi/files/handout_Rajiv_Rao.pdf

Romani, Patricia. 1992. Conservación del idioma en una comunidad italo-mexicana. México: Instituto Nacional de Antropología e Historia.

Sartor, Mario and Ursini, Flavia. 1983. Cent'anni di emigrazione: una comunitá veneta sugli altipiani del Messico. Treviso: Grafiche Antiga.

Simonet, Miquel. 2011. Intonational convergence in language contact: Utterance-final F0 contours in CatalanSpanish early bilinguals. Journal of the International Phonetic Association 41,157-184.

Sosa, Juan Manual. 1999. La entonación del español: su estructura fónica, variabilidad y dialectología. Madrid: Catedra.

Willis, Erik. 2005. Tonal levels in Puebla Mexico Spanish declaratives and absolute interrogatives. In Randall Gess \& Ed Rubin (eds.), Theoretical and experimental approaches to Romance linguistics: Selected papers from the 34th Linguistic Symposium on Romance Languages (LSRL), 351-363, Amsterdam: John Benjamins.

Zago Bronca, Jose Agustin. 2007. Los Cuah'tatarame de Chipíloc. 2nd edition.

Zilli Manica, Jose Benigno. 1981. Italianos en México. Documentos para la historia de los colonos italianos en México. Xalapa, Veracruz: Ediciones San José. 